OPEN ACCESS

Edited by:

Lluis Tort,

Universitat Autònoma de

Barcelona, Spain

Reviewed by:

Hai-peng Liu,

Xiamen University, China

Loriano Ballarin,

Università degli Studi di Padova,

Italy

${ }^{*}$ Correspondence:

Lingling Wang

wanglingling@dlou.edu.cn;

Linsheng Song

Ishsong@dlou.edu.cn

Specialty section:

This article was submitted to

Comparative Immunology,

a section of the journal

Frontiers in Immunology

Received: 30 November 2017

Accepted: 31 January 2018

Published: 26 February 2018

Citation:

Liu Z, Wang L, Lv Z, Zhou Z,

Wang W, Li M, Yi Q, Qiu L and

Song L (2018) The Cholinergic and

Adrenergic Autocrine Signaling

Pathway Mediates

Immunomodulation in Oyster

Crassostrea gigas.

Front. Immunol. 9:284.

doi: 10.3389/fimmu.2018.00284

\section{The Cholinergic and Adrenergic Autocrine Signaling Pathway Mediates Immunomodulation in Oyster Crassostrea gigas}

\author{
Zhaoqun Liu' ${ }^{1,2,3}$, Lingling Wang ${ }^{1,2 *}$, Zhao Lv ${ }^{3,4}$, Zhi Zhou', Weilin Wang ${ }^{1}$, Meijia Li ${ }^{3,4}$, \\ Qilin Yi', Limei Qiu ${ }^{3}$ and Linsheng Song ${ }^{1,2 *}$
}

'Liaoning Key Laboratory of Marine Animal Immunology, Dalian Ocean University, Dalian, China, ${ }^{2}$ Laboratory of Marine Fisheries Science and Food Production Processes, Qingdao National Laboratory for Marine Science and Technology, Qingdao, China, ${ }^{3}$ Key Laboratory of Experimental Marine Biology, Institute of Oceanology, Chinese Academy of Sciences, Qingdao, China, ${ }^{4}$ University of Chinese Academy of Sciences, Beijing, China, ${ }^{5}$ Key Laboratory of Tropical Biological Resources of Ministry of Education, Hainan University, Haikou, China

It is becoming increasingly clear that neurotransmitters impose direct influence on regulation of the immune process. Recently, a simple but sophisticated neuroendocrineimmune (NEI) system was identified in oyster, which modulated neural immune response via a "nervous-hemocyte"-mediated neuroendocrine immunomodulatory axis (NIA)-like pathway. In the present study, the de novo synthesis of neurotransmitters and their immunomodulation in the hemocytes of oyster Crassostrea gigas were investigated to understand the autocrine/paracrine pathway independent of the nervous system. After hemocytes were exposed to lipopolysaccharide (LPS) stimulation, acetylcholine (ACh), and norepinephrine (NE) in the cell supernatants, both increased to a significantly higher level (2.71- and 2.40-fold, $p<0.05)$ comparing with that in the control group. The mRNA expression levels and protein activities of choline O-acetyltransferase and dopamine $\beta$-hydroxylase in hemocytes which were involved in the synthesis of ACh and NE were significantly elevated at $1 \mathrm{~h}$ after LPS stimulation, while the activities of acetylcholinesterase and monoamine oxidase, two enzymes essential in the metabolic inactivation of ACh and NE, were inhibited. These results demonstrated the existence of the sophisticated intracellular machinery for the generation, release and inactivation of ACh and NE in oyster hemocytes. Moreover, the hemocyte-derived neurotransmitters could in turn regulate the mRNA expressions of tumor necrosis factor (TNF) genes, the activities of superoxide dismutase, catalase and lysosome, and hemocyte phagocytosis. The phagocytic activities of hemocytes, the mRNA expressions of TNF and the activities of key immune-related enzymes were significantly changed after the block of ACh and NE receptors with different kinds of antagonists, suggesting that autocrine/paracrine self-regulation was mediated by transmembrane receptors on hemocyte. The present study proved that oyster hemocyte could de novo synthesize and release cholinergic and adrenergic neurotransmitters, and the hemocyte-derived ACh/NE could then execute a negative regulation on hemocyte phagocytosis and synthesis of immune effectors with similar autocrine/paracrine signaling pathway identified in vertebrate macrophages. Findings in the present study demonstrated that the immune and neuroendocrine system evolved from a common origin and enriched our knowledge on the evolution of NEl system.

Keywords: Crassostrea gigas, autocrine/paracrine, hemocyte, neurotransmitter, membrane receptor, immune regulation 


\section{INTRODUCTION}

The nervous and endocrine systems regulate the immune system through releasing neurotransmitters, neuropeptides, and endocrine hormones as they modulate the other physiological activities (1). Recently, it has been realized that neurotransmitters derived from sources outside the nervous and endocrine systems, especially from immune system, can also serve as immunomodulators (2). The immune cell-derived neurotransmitters can bind to autocrine receptors on their own, exerting a considerable and reciprocal influence on the function of immune system (3). By far, such neuroendocrine autocrine/paracrine signaling has been well studied in vertebrates. The dendritic cells, leukocytes, and lymphocytes can synthesize and/or release classical neurotransmitters, including acetylcholine (ACh), dopamine (DA), serotonin (5-HT), and glutamate (4-7). These neurotransmitters in turn exert diverse effects during inflammation via autocrine/paracrine signaling pathways (2). For instance, DA and glutamate are able to interact directly with T-cell expressed receptors, leading to the activation or suppression of various T-cell functions including cytokine secretion, proliferation, integrin-mediated adhesion, and migration (8-12).

Comparing with model species, study on the neuroendocrine immune (NEI) regulation in invertebrates is still at the very outset. Most of the previous research focused on the immunomodulation of neurotransmitters released from neuroendocrine system. For instance, catecholamines (CAs), ACh, 5-HT, $\gamma$-aminobutyric acid (GABA), histamine, enkephaline (ENK), glutamic acid (GA), neuropeptide Y (NPY), and nitric oxide (NO) have been identified from the nervous and endocrine tissues in mollusks $(13,14)$. These neurotransmitters conduct neural immune regulation through a nervous-hemocyte neuroendocrine immunomodulatory axis (NIA)-like pathway, modulating both cellular and humoral immune activities in mollusk (15). Astonishingly, recent studies have illustrated that molluskan immune system can also synthesize neurotransmitters and may conduct autocrine/paracrine immune regulation. The key enzymes for CAs synthesis [dopamine $\beta$-hydroxylase (DBH)] and ACh degradation [acetylcholinesterase (AChE)] are reported to be present in molluskan hemocytes (16-18), and ACh and NE can be detected in hemolymph $(17,19,20)$. These findings imply the existence of cholinergic and adrenergic autocrine/paracrine pathways in molluskan hemocytes, which mediate neural immunomodulation at cellular level.

Circulating immunocytes play the most important roles in both neural immune regulation generated by nervous-derived neurotransmitters and autocrine/paracrine immune regulation conducted by cell-derived neurotransmitters $(2,21)$. Moreover, in both vertebrates and invertebrates, immunocytes act as fundamental players in the crosstalk between the NEI systems since they display significant overlap in molecular components and physiological functions (22). Numerous morphological and functional studies have indicated that there is a common pool of molecules shared by the immune and neuroendocrine systems, and there should be a common evolutionary origin for the two systems in both invertebrates and vertebrates (23). Therefore, the neuroendocrine autocrine/paracrine signaling existing in immunocytes exhibits perfect example for this hypothesis, and study on the neuroendocrine autocrine/paracrine pathway in invertebrate hemocytes can also provide insights into the evolution of the NEI system.

The complexity of immune and neuroendocrine components in mammals has prompted corresponding studies in simpler models. Among these, mollusks have been considered as valuable model for analyzing the basic patterns of the immune and neuroendocrine interactions (22) since they are the most primitive organisms evolved with a sophisticated NEI system (24), in which the circulating hemocytes are described as the "immunemobile brain" for their ability to recognize a variety of stimuli and to set up sophisticated responses (25). Most of the previous studies focused mainly on the immune response of hemocytes mediated by neurotransmitters, while their potentials to produce neurotransmitters were rarely mentioned. The aims of the present study are to (1) confirm the de novo synthesis of cholinergic and adrenergic neurotransmitters in oyster hemocytes, (2) investigate the immunomodulation of cholinergic and adrenergic systems mediated by hemocytes, and (3) evaluate the immunological activity of autocrine/paracrine neurotransmitters at cellular level. Investigation on the cholinergic and adrenergic autocrine immunomodulation in oyster hemocytes will enrich our knowledge about the common origin of NEI systems, as well as the evolution of NEI system.

\section{MATERIALS AND METHODS}

\section{Oysters and Primary Culture of Hemocytes}

Oysters Crassostrea gigas (with an average of $150 \mathrm{~mm}$ in shell height) were collected from a local farm in Qingdao, Shandong Province, China, and maintained in aerated seawater at $18^{\circ} \mathrm{C}$ for 2 weeks before processing.

Oyster hemolymph was aspirated from the blood sinus with a thin syringe, and centrifuged at $800 \mathrm{~g}$ to harvest the hemocytes. The hemolymph from five oysters was pooled together, and there were three parallel pools for each test. Primary culture of oyster hemocytes was carried out based on the protocol described by Jiang et al. (26). The cell viability was detected by Trypan Blue exclusion technique using commercial kit (Beyotime Biotechnology).

All animal-involving experiments of this study were approved by the Ethics Committee of the Institute of Oceanology, Chinese Academy of Sciences.

\section{Lipopolysaccharide (LPS) Stimulation, Antagonist Treatment, and Sample Collection}

For the LPS stimulation experiment, hemocytes were incubated with $100 \mathrm{ng} \mathrm{mL}^{-1}$ of LPS origin from Escherichia coli 0111:B4 (Sigma) for $30 \mathrm{~min}$ and $1 \mathrm{~h}$, respectively, while the same volume of PBS (Gibco, pH 7.4) was added in the negative control (Neg-Ctrl) group.

The incubation of antagonists for neurotransmitter receptors on oyster hemocytes was performed according to the description in previous studies to explore whether hemocyte-derived neurotransmitters could exert autocrine/paracrine immune regulation 
via cell-surface receptors (27-29). In the present study, nonselective nicotinic acetylcholine receptor (nAChR) antagonist mecamylamine hydrochloride (Tocris Bioscience) was employed in the non-selective $\mathrm{nAChR}$ antagonists group, while $\alpha-7 \mathrm{nAChR}$ antagonist $\alpha$-Bungarotoxin (Tocris Bioscience) was added in the $\alpha-7$ nAChR antagonists group. In order to block the muscarinic acetylcholine receptors (mAChRs) on the hemocyte surface, five antagonists including pirenzepine (Tocris Bioscience), AFDX 116 (Tocris Bioscience), 4-DAMP (Tocris Bioscience), PD102807 (Tocris Bioscience), and darifenacin (Sigma) specific for the $\mathrm{m} 1$ to $\mathrm{m} 5 \mathrm{mAChRs}$, respectively, were used in the $\mathrm{m} 1-\mathrm{m} 5$ mAChRs antagonists groups (30). In addition, the mixture of doxazosin mesylate [specific antagonists for $\alpha-1$ adrenergic receptor (A1AR), Tocris Bioscience] and idazoxan yohimbine [specific antagonists for $\alpha-2$ adrenergic receptor (A2AR), Tocris Bioscience] were added in the $\alpha$-antagonists group to inhibit the binding activities of $\alpha$ adrenergic receptors (AARs), while propranolol (Tocris Bioscience), specific antagonist for $\beta$-adrenergic receptor (BAR), was added in the $\beta$-antagonist group to block BARs (31-33). Furthermore, in order to explore the synergistic immunomodulation of $\mathrm{ACh}$ and NE, the mixture of different kinds of antagonists was employed to block all AChRs and ARs. In the $\alpha-7+$ m1-5 group, $\alpha-7$ nAChR antagonist ( $\alpha$-Bungarotoxin) and $\mathrm{m} 1$ to $\mathrm{m} 5 \mathrm{mAChR}$ antagonists (pirenzepine, AFDX 116, 4-DAMP, PD102807, and darifenacin) were added, while in $\alpha+\beta$ group, A1AR antagonists (doxazosin mesylate), A2AR antagonist (idazoxan yohimbine) and BAR antagonist (propranolol) were used to block the ARs and BRs on hemocyte surface. All antagonists were employed at a final concentration of $10.0 \mu \mathrm{mol} \mathrm{L} \mathrm{L}^{-1}$ and incubated with hemocytes for $1 \mathrm{~h}$ before LPS stimulation $\left(100 \mathrm{ng} \mathrm{mL}^{-1}\right)$. Hemocytes incubated with Leibovitz-15 (L-15) medium for $1 \mathrm{~h}$ and subsequently with LPS stimulation were employed as Vehicle group, and cells incubated with PBS instead of antagonists or LPS were treated as the Neg-Ctrl group.

Hemocytes from different groups were collected at $3 \mathrm{~h}$ after LPS stimulation for the subsequent determinations of phagocytosis,
mRNA expressions and enzyme activities. Three replicates were considered for each assay.

\section{RNA Extraction and Quantitative Real-time PCR}

Trizol reagent was used to extract the total RNA from oyster hemocytes. DNase I (Promega) and oligo (dT)-adaptor were then employed to synthesize the cDNA library. Next, the constructed cDNA library was used to evaluate the mRNA expression levels of three oyster tumor necrosis factors (TNFs) including CGI_10005109, CGI_10005110, and CGI_10006440, by using SYBR green quantitative real-time PCR technique (34). The amplified fragment (168 bp) of oyster elongation factor (CgEF, CGI_10012474) was employed as the endogenous control. The primers used in the present study (Table 1) have been verified in previous research according to the dilution curve detected by the 7500 real-time PCR system (Applied Biosystem) (35). Three replicates were detected for each sample and all data were shown in terms of relative expression using the $2^{-\Delta \Delta \mathrm{Ct}}$ method (36).

\section{Quantification of ACh and NE in Hemocyte Supernatants}

The contents of ACh and NE in the primarily cultured hemocyte supernatants after LPS stimulation were determined using the ACh and NE ELISA kit (Abnova) according to previous reports $(26,37)$. The quantification of samples was conducted by comparing the absorbance with a reference curve. There were about $10^{5}$ cells in each well, and three replicates were employed for each control and experimental group.

\section{Measurements of Enzyme Activity in Oyster Hemocytes}

The activities of two key ACh/NE synthesis enzymes in oysters, choline $\mathrm{O}$-acetyltransferase (CgChAT) and dopamine $\beta$-hydroxylase $(\mathrm{CgDBH})$, as well as two key $\mathrm{ACh} / \mathrm{NE}$ degradation enzymes, acetylcholinesterase $(\mathrm{CgAChE})$ and monoamine oxidase

TABLE 1 | Sequences of the primers used in the experiment.

\begin{tabular}{|c|c|c|}
\hline Primer & Sequence $\left(5^{\prime}-3^{\prime}\right)$ & Sequence information \\
\hline P1 (forward) & CGCAATGGTCGCTTGGTGGTC & Real-time CgTNF (CGI_10005109) primer \\
\hline P2 (reverse) & CGTAGGGGCGGAAGGTCTCG & Real-time CgTNF (CGI_10005109) primer \\
\hline P3 (forward) & CAACGGTCTAACTTACCATCCAAAC & Real-time CgTNF (CGI_10005110) primer \\
\hline P4 (reverse) & TGGTGGTAGATAAAATGGGACAGTG & Real-time CgTNF (CGI_10005110) primer \\
\hline P5 (forward) & ATTGGAGCACCTGGAGGATAAG & Real-time CgTNF (CGI_10006440) primer \\
\hline P6 (reverse) & CAGTCTTCCGTGCTGGTATITC & Real-time CgTNF (CGI_10006440) primer \\
\hline P7 (forward) & TGAGTCCAGATTCCTITATCCAGTTAG & Real-time CgChAT (CGl_10023267) primer \\
\hline P8 (reverse) & TCCAAAGCATCTGGGGTGTTAG & Real-time CgChAT (CGI_10023267) primer \\
\hline P9 (forward) & GGTAATAACGAAAGGAAACGAAG & Real-time CgDBH (CGI_10027734) primer \\
\hline P10 (reverse) & CACCGATAACTTCCCGACAC & Real-time CgDBH (CGI_10027734) primer \\
\hline P11 (forward) & АССТАТTСАATСАTСGСТССТСС & Real-time CgAChE (CGI_10019411) primer \\
\hline P12 (reverse) & TCTCПTATACGTGTGAAGGGGC & Real-time CgAChE (CGI_10019411) primer \\
\hline P13 (forward) & AGACAACTGATGGAGTGACGGTG & Real-time CgMAO (CGI_10022845) primer \\
\hline P14 (reverse) & TCCAAAAAGGGGTCTTGTAGTAGC & Real-time CgMAO (CGI_10022845) primer \\
\hline P15 (forward) & АTCCTTCСTССАTСTCGTCCT & Real-time CgEF (CGl_10012474) primer \\
\hline P16 (reverse) & GGCACAGTTCCAATACCTCCA & Real-time CgEF (CGI_10012474) primer \\
\hline M13-47 & CGCCAGGGTITCCCAGTCACGAC & pMD18-T simple vector primer \\
\hline RV-M & GAGCGGATAACAATITCACACAGG & pMD18-T simple vector primer \\
\hline P17 (forward) & GGCCACGCGTCGACTAGTACT $17_{17}$ & Oligo(dT)-adaptor \\
\hline
\end{tabular}


(CgMAO), were measured in the present study. CgChAT activity was determined using a kit (Jiancheng, A079; Nanjing) according to its protocol. The cell lysates was first incubated with reagents $1-6$ provided by the kit at $37^{\circ} \mathrm{C}$ for $5 \mathrm{~min}$, followed by terminating the reaction in boiling water for $2 \mathrm{~min}$. The evaluation of $\mathrm{CgDBH}$ activity was conducted with two enzymatic reactions according to the previous description (38). In the first reaction, tyramine was added to the homogenate, and it could be converted to octopamine by $\mathrm{DBH}$. In the subsequent second reaction, the enzymatically formed octopamine was further converted to N-methyl octopamine by the added PNMT. S-adenosylmethionine served as a methyl donor, and the amount of $\mathrm{C}^{14}-\mathrm{N}$-methyl octopamine was proportional to $\mathrm{DBH}$ activity. In addition, $\mathrm{CgAChE}$ activity was determined based on the colorimetric method (39). First, $330 \mu \mathrm{L}$ of PBS, $20 \mu \mathrm{L}$ of 5,5'-dithiobis-(2-nitrobenzoic acid) (DTNB, $\left.0.0076 \mathrm{~mol} \mathrm{~L}^{-1}\right)$ working as chromogenic agent, as well as $100 \mu \mathrm{L}$ of hemocyte lysates were mixed and placed in a 96-well plate. Then, $10 \mu \mathrm{L}$ of acetylthiocholine iodide (ATC, $0.076 \mathrm{~mol} \mathrm{~L}^{-1}$ ) were added and the enzyme activity was evaluated. Wells without ATC or cell lysates were designated as controls and spontaneous substrate hydrolyzates was determined. The absorbance of 2-nitro-5-thiobenzoate anion was measured at $405 \mathrm{~nm}$. Finally, the activity of CgMAO was determined as described by Zhou et al. (16), taking the metabolism rate of serotonin as its activity. Three replicates were conducted for each assay.

The activities of superoxide dismutase (SOD), catalase (CAT), and lysozyme (LYZ) in hemocyte lysates were then measured. And the determinations were conducted using kits from Jiancheng (Nanjing).

\section{Determination of Hemocyte Phagocytic Activity}

The phagocytic activity of hemocytes was measured according to the previous report (34). The concentration of hemocytes, resuspended in seawater, was adjusted to $1.0 \times 10^{6}$ cells $\mathrm{mL}^{-1}$ and $500 \mu \mathrm{L}$ of hemocyte resuspension was incubated with $5 \mu \mathrm{L}$ of dead, FITC-labeled Vibrio splendidus $\left(1.0 \times 10^{9} \mathrm{CFU} \mathrm{mL} \mathrm{mL}^{-1}\right)$ at room temperature for $1 \mathrm{~h}$. After washing in PBS, hemocytes were centrifuged to discard un-ingested bacteria. The intensity of FITC fluorescence was measured by flow cytometry, and the phagocytic activity was calculated as (number of phagocytic cells with ingested bacteria)/(number of phagocytes). Three replicates were determined for each assay.

\section{Statistical Analysis}

All data were presented as means $\pm \mathrm{SD}$, and subjected to one-way analysis of variance in SPSS software, followed by multiple comparisons (S-N-K). Differences were considered significant at $p<0.05$.

\section{RESULTS}

\section{Concentration Changes of ACh and NE in Hemocyte Supernatants after LPS Stimulation}

The concentration of ACh and NE in supernatants of hemocyte at $30 \mathrm{~min}, 1,3$, and $6 \mathrm{~h}$ after LPS stimulation was quantified to evaluate the de novo production of cholinergic and adrenergic neurotransmitters (Figure 1). The concentrations of ACh and NE in hemocyte supernatants both increased to a significantly higher level (2.71- and 2.40-fold, $p<0.05)$ comparing with that in the Neg-Ctrl group at $1 \mathrm{~h}$ after LPS stimulation (Figures 1A,B). No significant changes of $\mathrm{ACh}$ and NE contents were observed at other time points after LPS stimulation $(p>0.05)$. Our results indicated that LPS stimulation could quickly trigger oyster hemocyte to de novo produce cholinergic and adrenergic neurotransmitters.

\section{Expression and Activity Variations of Key Enzymes in ACh/NE Metabolism after LPS Stimulation}

The mRNA expression levels and protein activities of CgChAT, $\mathrm{CgDBH}, \mathrm{CgAChE}$, and CgMAO were examined to further ascertain the de novo production and degradation of $\mathrm{ACh}$ and $\mathrm{NE}$ in oyster hemocytes at $30 \mathrm{~min}$ and $1 \mathrm{~h}$ after LPS stimulation (Figure 1). In general, there were low mRNA expression levels in hemocytes for all the four examined genes under normal status. Except for the activity of $\mathrm{CgDBH}$, the mRNA expressions and protein activities kept relatively stable levels at $30 \mathrm{~min}$ in most of the groups, while significant changes were observed at $1 \mathrm{~h}$ posttreatment. At $1 \mathrm{~h}$ after LPS stimulation, the mRNA expression of CgChAT was significantly upregulated, which was 3.67 -fold of that in the Neg-Ctrl group (Figure 1C, $p<0.05$ ), and the expression of CgDBH also increased to 4.67 -fold of that in the Neg-Ctrl group (Figure 1D, $p<0.05$ ). Similarly, the enzyme activities of $\mathrm{CgChAT}$ and $\mathrm{CgDBH}$ were upregulated to 1.34 -fold and 2.04fold comparing with that in the Neg-Ctrl group at $1 \mathrm{~h}$ after LPS exposure (Figures 1E,F, $p<0.05$ ). Only in Figure 1F, the activity of $\mathrm{CgDBH}$ at $30 \mathrm{~min}$ after LPS stimulation was significantly higher $(p<0.01)$ than that in control group.

Conversely, both the mRNA expression levels and protein activities of CgAChE significantly decreased at $1 \mathrm{~h}$ after LPS stimulation, which were 0.42 -fold and 0.74 -fold of that in the NegCtrl group, respectively (Figures 1G,I, $p<0.05$ ). As for CgMAO, although its mRNA transcripts in the LPS group remained to a comparable level with that in the Neg-Ctrl group (Figure 1H, $p>0.05$ ), its protein activity was severely downregulated to the 0.50 -fold of that in the Neg-Ctrl group (Figure 1J, $p<0.05$ ). These results revealed the existence of the sophisticated intracellular machinery for the generation, release and inactivation of $\mathrm{ACh}$ and NE in oyster hemocytes.

\section{Phagocytic Activities after Treatments with Receptor Antagonists and LPS}

In order to understand the possible mediation of hemocytederived ACh to cellular immune response, the phagocytic activity of oyster hemocyte after the incubation of ACh receptor antagonist followed by the LPS stimulation for $3 \mathrm{~h}$ was determined (Figure 2). The phagocytic activity of hemocyte in the non-selective nAChR antagonist group (35.6\%) was significantly higher than that $(25.87 \%)$ in Vehicle group in which receptors were not blocked before LPS stimulation (Figure 2A, $p<0.05$ ). Significant increase of phagocytic activity was also observed after the block of $\alpha-7 \mathrm{nAChR}$ with specific antagonist (33.73 vs. 

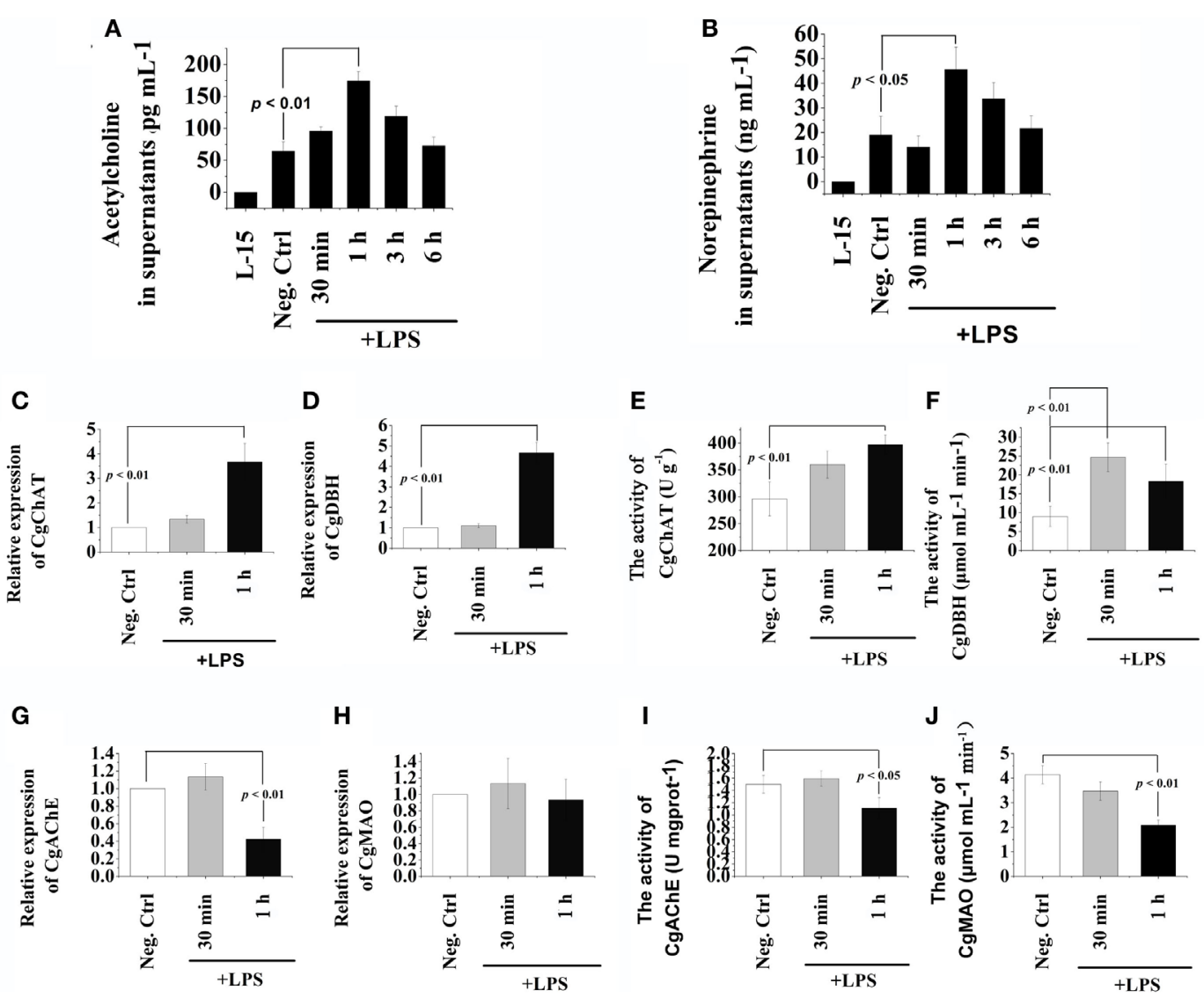

FIGURE 1 | Release of acetylcholine (Ach) and norepinephrine (NE) from oyster hemocytes and the presence of ACh/NE-producing enzymes in hemocytes. (A,B) After isolation and primary cell culture, hemocytes were incubated with $100 \mathrm{ng} \mathrm{mL}^{-1}$ of lipopolysaccharide (LPS) in vitro, while the same volume of PBS was added in the negative control (Neg-Ctrl) group. Hemocytes incubated with Leibovitz-15 (L-15) medium for $1 \mathrm{~h}$ and subsequently with LPS stimulation were employed as Vehicle group. Cellular supernatant fluids were collected as a function of time thereafter and then analyzed by enzyme-linked immunosorbent assay for acetylcholine (A) and norepinephrine (B). (C-H) After stimulation with $100 \mathrm{ng} \mathrm{mL} \mathrm{mL}^{-1}$ of LPS in vitro, mRNA from hemocytes were sampled and subjected to real-time PCR analysates for choline O-acetyltransferase (C), dopamine beta-hydroxylase (D), acetylcholinesterase (G), and monoamine oxidase (H). (E,F,I,J), After stimulation with $100 \mathrm{ng} \mathrm{mL}^{-1}$ of LPS in vitro, protein from hemocytes were extracted and subjected to enzyme activity measurement of choline O-acetyltransferase (E), dopamine beta-hydroxylase (F), acetylcholinesterase (I), and monoamine oxidase (J). Each bar represents $N=6$ samples. All data are presented as means \pm SD.

$25.87 \%$ in Vehicle group, $p<0.05)$. In addition, for the block of mAChRs, the phagocytic activity increased significantly from $26.4 \%$ in Vehicle group to $35.03 \%$ in $\mathrm{m} 5 \mathrm{mAChR}$ antagonist group (Figure 2B, $p<0.05$ ). No significant changes were observed in m1-4 antagonist treatment groups (Figure $\mathbf{2 B}, p>0.05$ ).

The phagocytic activities of oyster hemocytes after the incubation of NE receptor antagonist were also determined. The phagocytic activity in Vehicle group (without receptor block before LPS stimulation) was significantly upregulated to $26.23 \%$ (Figure 2C, $p<0.05)$ comparing with that in the Neg-Ctrl group (11.87\%). After inhibiting AARs, a significant increase of hemocyte phagocytic activity $(36.37 \%)$ was detected as compared with that in Vehicle group (Figure $2 \mathrm{C}, p<0.05$ ). However, the phagocytic activity of hemocyte showed no significant change $(p>0.05)$ after the incubation of BAR antagonist. These results suggested that the hemocytederived $\mathrm{ACh}$ and $\mathrm{NE}$ could in turn modulate the immune responses of oyster hemocytes through autocrine/paracrine pathways via the mediation of nAChRs, $\mathrm{m} 5 \mathrm{mAChR}$ and AARs.

\section{Changes of TNF Expressions in Oyster Hemocytes after Receptor Inhibition and LPS Stimulation}

The mRNA expression levels of three oyster TNFs (CGI_10005109, CGI_10005110, and CGI_10006440) in hemocytes were examined by quantitative real-time PCR after receptor block and LPS stimulations to further explore the autocrine/paracrine immunomodulation patterns in oyster hemocytes. As shown in Figures 3A-C, the mRNA expressions of CGI_10005109, CGI_10005110, and CGI_10006440 all increased to a significant level at $3 \mathrm{~h}$ post-LPS stimulation $(p<0.05)$. After the inhibition of ARs on the surface of hemocytes by the incubation of $\alpha+\beta$ AR antagonists, the mRNA expression of CGI_10005109 and CGI_10006440 was significantly upregulated to 1.45-fold and 1.65-fold that in Vehicle group, respectively (Figures 3A,C, $p<0.05)$. No obvious change of the CGI_10005110 expression level was detected (Figure 3B, $p>0.05$ ). 

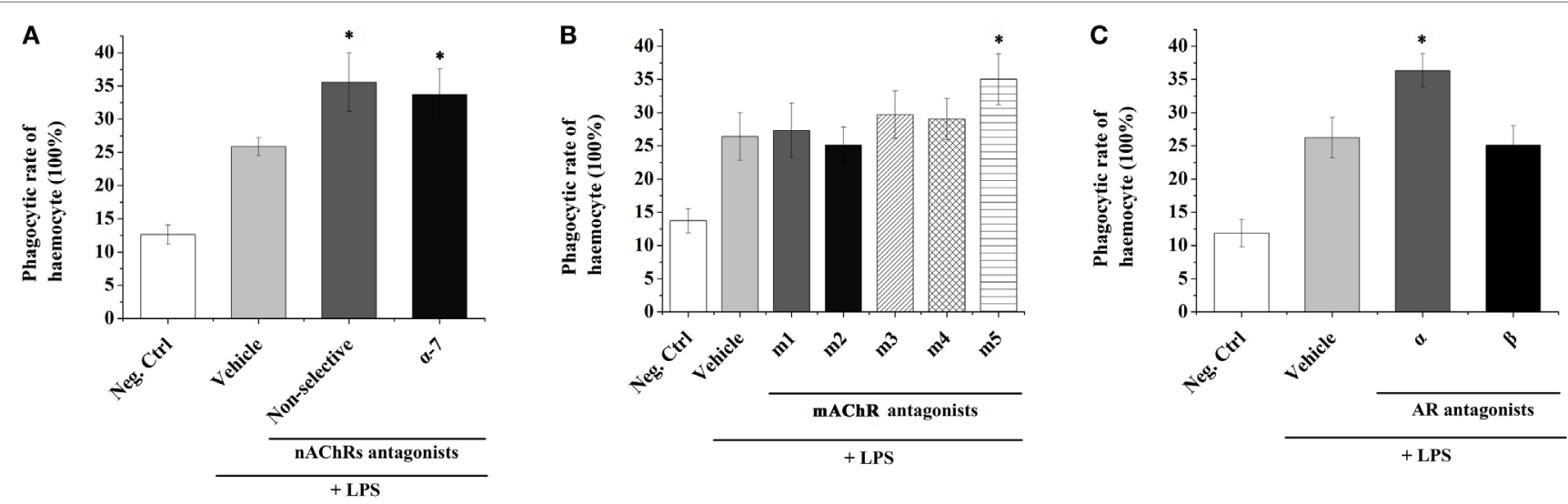

FIGURE 2 | Transmembrane receptors mediate the immune regulation of hemocyte-derived acetylcholine (Ach) and norepinephrine (NE). The immune response (represented by hemocyte phagocytic activity) was induced by lipopolysaccharide (LPS). Adrenoceptors (A), muscarinic (B), and nicotinic (C) Ach receptors were blocked pharmacologically to explore their functions in mediating immune regulation of hemocyte-derived ACh and NE. Each bar represents $N=6$ samples. All data are presented as mean \pm SD. Asterisks indicate statistical significance comparing with the vehicle control.

After AChRs were inhibited by nAChRs and mAChRs antagonists, the mRNA expression of CGI_10006440 increased to 1.49 -fold of that in Vehicle group (Figure 3C, $p<0.05$ ). No obvious variations of the expressions of CGI_10005110 and CGI_10006440 were observed after the incubation of AChRs antagonists (Figures 3A,B, $p>0.05$ ). Our results illustrated that hemocyte-derived neurotransmitters could regulate cytokine production in oyster hemocyte through autocrine/paracrine pathways.

\section{Alteration of Immune-Related Enzyme Activities after Receptor Block and LPS Stimulation}

In order to investigate the humoral immune regulation induced by hemocyte-derived ACh and NE, the activities of SOD, CAT, and LYZ were determined postreceptor antagonist incubation and LPS stimulation. As shown in Figures 3D-F, the activities of SOD, CAT, and LYZ were severely upregulated at $3 \mathrm{~h}$ post LPS stimulation. After the block of AChRs with antagonists, the activities of SOD and LYZ were significantly increased, which were 1.44- and 1.63-fold of that in Vehicle groups, respectively (Figures 3D,F, $p<0.05$ ), while no obvious change was observed in the $\alpha+\beta$ ARs blocking groups (Figures 3D-F, $p>0.05$ ). These results implied that hemocyte-derived neurotransmitters could regulate humoral immunity in oyster through autocrine/ paracrine pathways.

\section{DISCUSSION}

Neurotransmitters are traditionally considered as nerve-secreted molecules that trigger or inhibit neurosecretion (40). Yet, it is demonstrated that many vertebrate immune cells can also synthesize and/or release neurotransmitters to regulate immune function by autocrine signaling pathway (2), which offers a novel perspective in revealing the fine-tuning of immune regulation. In the present study, the possible capability of oyster hemocytes to produce cholinergic and adrenergic neurotransmitters was investigated to unveil the possible autocrine mechanism in marine invertebrates, and the immune regulation mediated by these immunocytederived neurotransmitters was further explored. ACh and NE concentrations in the cell culture medium significantly increased at $1 \mathrm{~h}$ post-LPS stimulation, and these neurotransmitters should be produced by in vitro cultured hemocytes. It was reported that noradrenaline and adrenaline levels in supernatants of human macrophages and polymorphonuclear cells increased significantly at $4 \mathrm{~h}$ after LPS exposure (6). CD $4^{+} \mathrm{T}$ cells contained substantially more ACh compared with $\mathrm{CD}^{+} \mathrm{T}$ cells or B cells, while the synthesis and release of ACh from lymphocyte were increased during mitogen (41). The present results indicated that oyster hemocytes can de novo produce neurotransmitters such as ACh and NE under LPS stimulation, like those immune cells in vertebrates.

$\mathrm{ACh}$ is synthesized from acetyl coenzyme A and choline by the enzyme ChAT (42), while NE is converted from DA by the activity of the enzyme $\mathrm{DBH}$ (43). ChAT is known as a rate-limiting enzyme in ACh synthesis (44), whereas DBH is a copper-containing enzyme that uses molecular oxygen and ascorbate to catalyze the addition of a hydroxyl group on the beta-carbon of dopamine to form norepinephrine (45). In the present study, the mRNA expressions and protein activities of $\mathrm{CgChAT}$ and $\mathrm{CgDBH}$ in hemocytes both increased dramatically at $1 \mathrm{~h}$ after LPS stimulation. These results suggested that oyster hemocytes possessed the molecular components to produce ACh and NE post LPS stimulation like mammalian phagocytes (6). Usually, the actions of neurotransmitters are terminated in three ways including reuptake into nerve terminals, diffusion into extracellular fluids and metabolic transformation (6). AChE and MAO are crucial enzymes for the degradation of ACh and NE $(2,22)$. In the present study, the mRNA expression levels of CgAChE decreased significantly at $1 \mathrm{~h}$ after LPS stimulation, and the activities of $\mathrm{CgAChE}$ and $\mathrm{CgMAO}$ also decreased (Figure 1). These results were consistent with the dramatic increase of $\mathrm{ACh}$ and NE concentrations after LPS stimulation (Figures 1A,B), suggesting that the degradation of ACh and NE was inhibited by the 


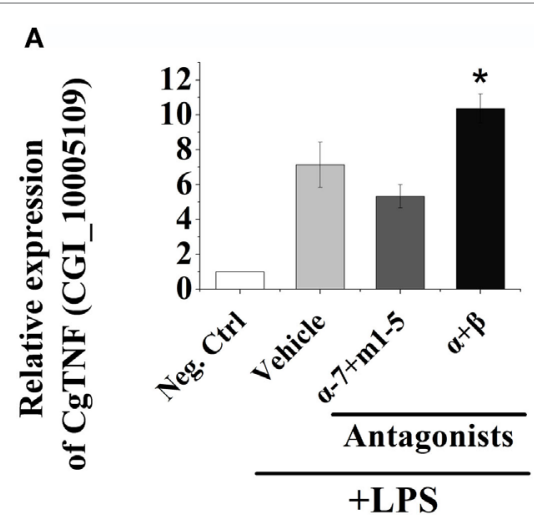

D

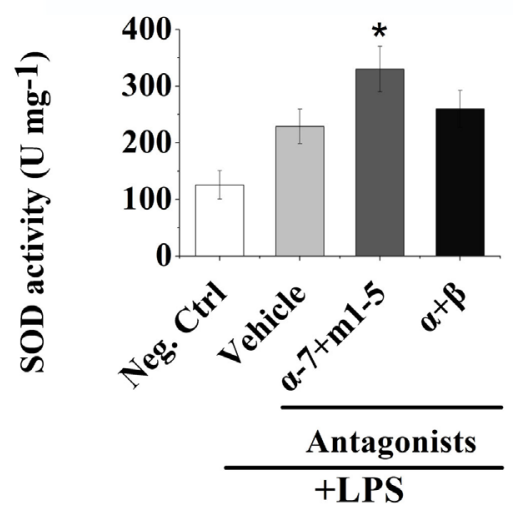

B
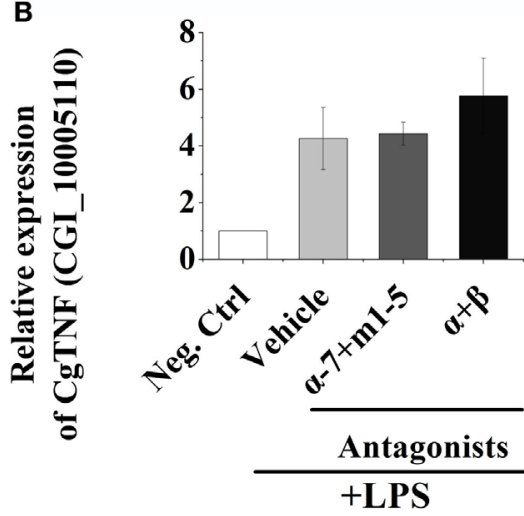

E

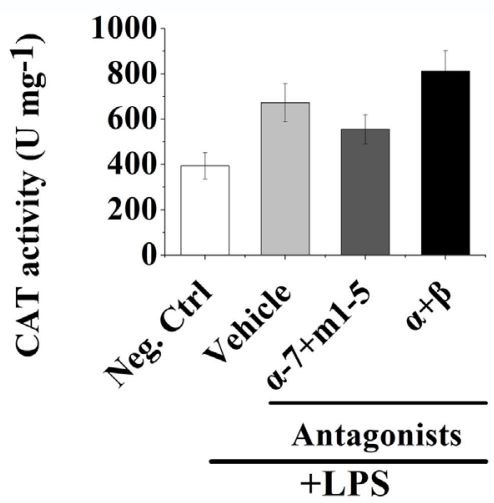

C

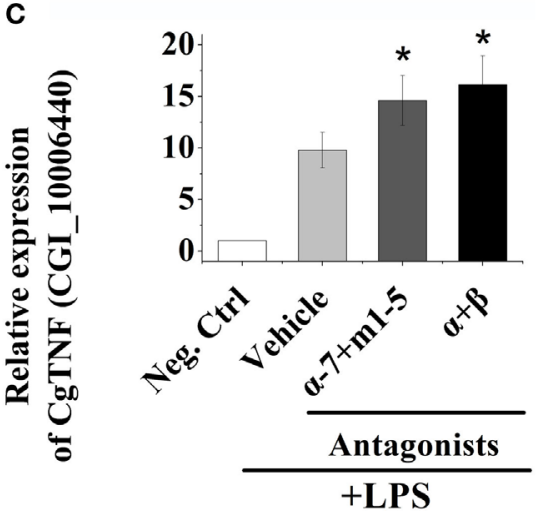

F

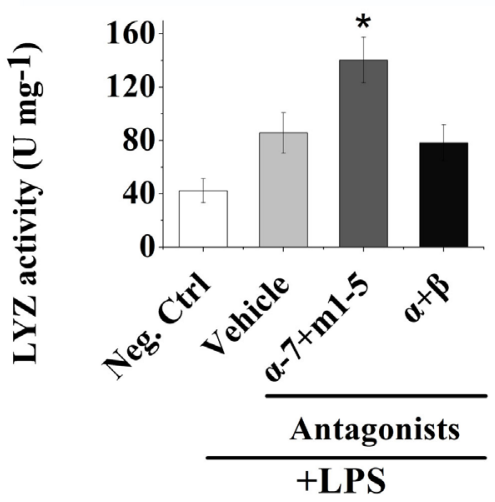

FIGURE 3 | Hemocyte-derived acetylcholine and norepinephrine regulate cellular and humoral immunity. (A-C) After stimulation with 100 ng mL ${ }^{-1}$ of lipopolysaccharide (LPS) in vitro, mRNA from hemocytes were sampled and subjected to real-time PCR analysates for three oyster tumor necrosis factor genes, CGI_10005109 (A), CGI_10005110 (B), and CGI_10006440 (C). (D-F) After stimulation with $100 \mathrm{ng} \mathrm{mL}^{-1}$ of LPS in vitro, protein from hemocytes were extracted and subjected to enzyme activity measurement of superoxide dismutase (D), catalase (E), and lysosome (F). Each bar represents $N=6$ samples. All data are presented as mean $\pm \mathrm{SD}$. Asterisks indicate statistical significance comparing with the vehicle control.

abundance of $\mathrm{ACh} / \mathrm{NE}$ that modulated immune response against LPS stimulation. With the characterization of both synthesizing and degradating enzymes in the metabolism of $\mathrm{ACh} / \mathrm{NE}$, our results ascertained the sophisticated cellular machinery for de novo generation, release and inactivation of $\mathrm{ACh} / \mathrm{NE}$ in oyster hemocytes.

Neurotransmitters are critical for the immune modulation by binding to their specific receptors on the surface of immune cells in vertebrates (46). For example, ACh can activate nAChR in macrophages of mammals to inhibit NF- $\mathrm{BB}$ signaling, thereby decreasing the production of proinflammatory cytokines, and finally causing severe inflammatory reaction and pathological responses (47). So far, receptors for many neurotransmitters including NE, ACh, ENK, 5-HT, and GABA have also been identified on the surface of bivalve hemocytes $(27,28,48-50)$, and this represents the molecular basis for the autocrine immune regulation in mollusks. To investigate the mediation of transmembrane neurotransmitter receptors during autocrine immunomodulation in mollusks, antagonists for ACh and NE receptors were employed to block their binding activities in vitro, and the fraction of phagocytizing oyster hemocytes were determined. As shown in our results, the phagocytic activities of oyster hemocytes increased significantly at $1 \mathrm{~h}$ after LPS stimulation in non-selective
nAChRs antagonist and $\mathrm{m} 5 \mathrm{mAChR}$ antagonist groups. nAChRs and $\mathrm{mAChRs}$ are characterized as two subtypes of AChRs based on their affinities and sensitivities to different ligands (nicotine/ muscarine) $(30,51)$. Both $\mathrm{nAChRs}$ and $\mathrm{mAChRs}$ are critical for the immune modulation such as the production of cytokines and modification of antibody synthesis in humans (52). Low-dose nicotine causes inhibition of TNF- $\alpha$, prostaglandin $\mathrm{E}_{2}$, and macrophage inflammatory protein- $1 \alpha$ production in LPS-activated monocytes, and these suppressive effects are mediated through $\alpha 7 \mathrm{nAChR}$ (53). Activation of T cells with phytohemagglutinin (PAH) and phorbol 12-myristate 13-acetate (PMA) upregulates the expression of ChAT and $\mathrm{m} 5 \mathrm{mAChR}$ genes via the protein kinase $\mathrm{C}(\mathrm{PKC})$ and mitogen-activated protein kinase pathways (54). In addition, it was found that ACh can inhibit phagocyte apoptosis and phagocytosis in oyster (34). Results in the current study suggest that hemocyte-derived ACh can trigger negative autocrine/paracrine immunomodulation in response to LPS stimulation via the mediation of $\mathrm{nAChR}$ and $\mathrm{m} 5 \mathrm{mAChR}$. As for the neurotransmitter NE, there were two main groups of receptors, AARs and BARs. AARs include the subtypes $\alpha-1$ (a Gq-coupled receptor) and $\alpha-2$ (a Gi-coupled receptor) (55). BARs include the subtypes $\beta-1, \beta-2$, and $\beta-3$, and all these three types are linked to Gs proteins (although $\beta-2$ also couples to 
Gi) (56). In the present study, the phagocytic activity of oyster hemocytes was significantly increased after the block of AARs as compared with that in control group, while similar results were not observed when BARs were inhibited. It was reported that AARs were indispensable mediators in the innate immunity. In the rat thymus, A1AR was colocalized with the monocyte/ macrophage marker CD68. Functional A1ARs were identified on murine RAW264 macrophages when phenylephrine and other PKC activating agents were used to initiate cell spreading (57). The present results suggested that $\mathrm{ACh}$ and NE released from hemocytes could repress the cellular immune response of oyster via the mediation of $\mathrm{nAChR}, \mathrm{m} 5 \mathrm{mAChR}$, and AAR.

The production of immune/inflammatory mediators including cytokines, chemokines, reactive oxygen species, and other immune effectors is modulated by activation of neurotransmitter receptors expressed on immune cells (58). For example, ARs can mediate the inhibition of TNF- $\alpha$ production caused by LPS stimulation in human monocytes (59). $\alpha 7 \mathrm{nAChRs}$ have been shown to negatively regulate the synthesis and release of TNF- $\alpha$ in macrophages (60), and stimulation of A2ARs subtype by exogenous or endogenous NE induced the release of TNF- $\alpha$ by murine peritoneal macrophages stimulated with LPS (61). Our previous research found that neurotransmitters in mollusks could also modulate both cellular and humoral immunity, and immune effectors, such as TNF- $\alpha$, SOD, CAT, and LYZ were produced during the response for neurotransmitter modulation $(14,62)$. In the present study, the immune regulatory functions of neurotransmitters released from hemocytes were investigated by in vitro experiments. LPS stimulation significantly upregulated the mRNA expressions of oyster TNF genes (CGI_10005109,CGI_10005110, and CGI_10006440), and the block of ARs with $\alpha+\beta$ ARs antagonists caused a significant increase in the mRNA expressions of CGI_10005109 and CGI_10006440, but not CGI_10005110. Inhibiting AChRs with antagonists could obviously increase the mRNA expression level of CGI_10006440. The activities of SOD and LYZ were severely increased after AChRs were blocked with antagonists. Our previous study found that the three TNF genes, especially CGI_10006440, were vital components of the signaling pathway for the neurotransmitter to modulate the endocrine system of oyster (34). Our results demonstrated for the first time that the hemocyte-derived ACh and NE could exert similar cellular and humoral immunomodulation through autocrine/paracrine pathways in oyster. Interestingly, cytokine (such as TNF- $\alpha$ ) production was mainly modulated by NE via ARs, while the synthesis

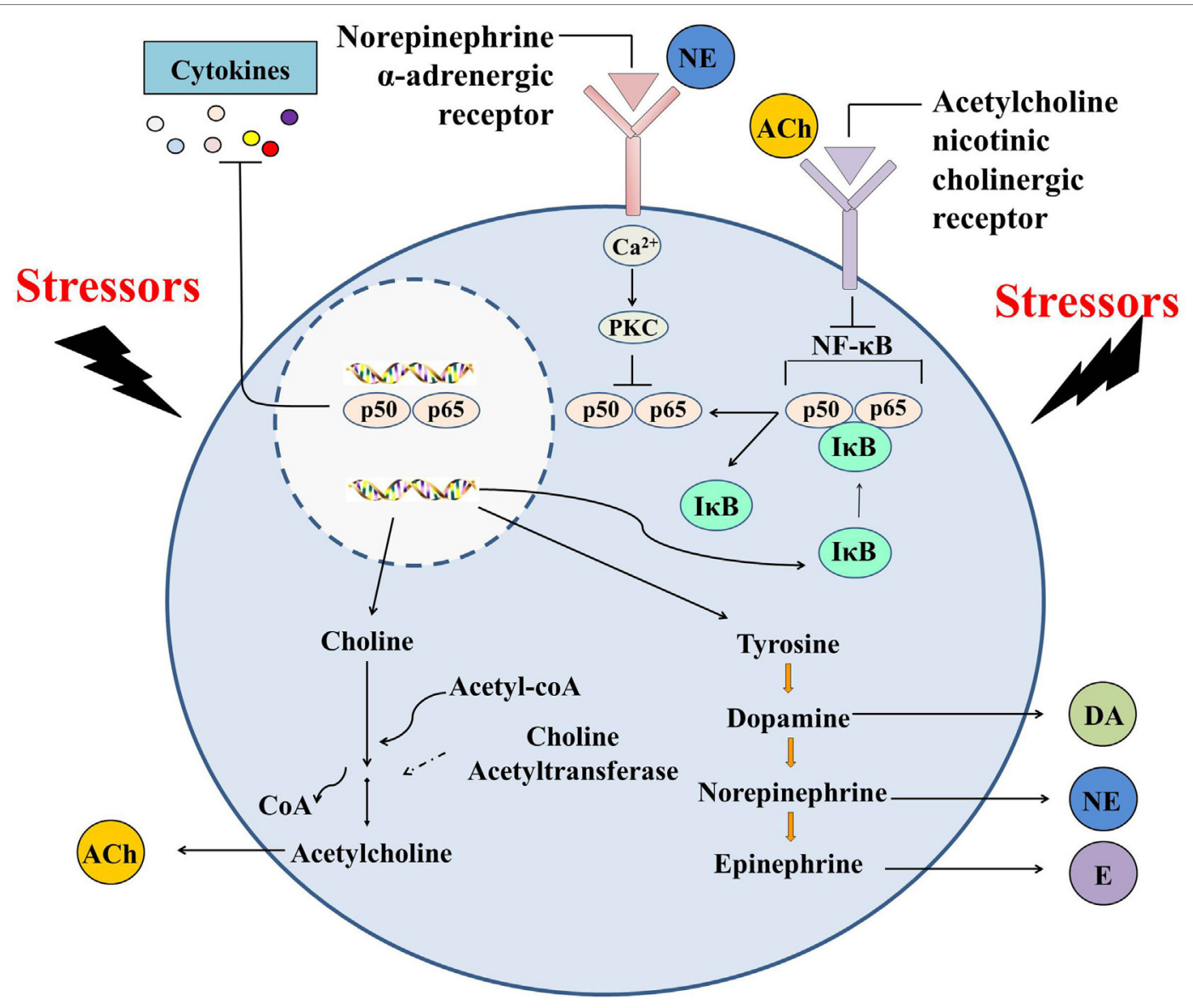

FIGURE 4 | Immunomodulation mediated by hemocyte-derived cholinergic and adrenergic neurotransmitters. Oyster hemocytes should represent similar immune and neuroendocrine functions as their counterparts in vertebrates (e.g., macrophages) and play an indispensable role in autocrine/paracrine immunomodulation, demonstrating that they could serve as suitable model for the study of the origin and evolution of the immune cells. 
of SOD and LYZ was basically regulated by ACh through AChRs in oyster hemocytes during autocrine/paracrine immunomodulation. Such results had never been reported in other species and needed further exploration in the future.

Taken together, oyster hemocytes are found to be capable of de novo synthesizing and releasing $\mathrm{ACh}$ and $\mathrm{NE}$, indicating that they are evolutionary primitive immunocytes with the ability to produce cholinergic and adrenergic neurotransmitters. Oyster hemocytes show similar immune and neuroendocrine functions as their counterparts in vertebrates (e.g., macrophages) and play an indispensable role in autocrine/paracrine immunomodulation (Figure 4), demonstrating that they can serve as suitable model for the study of the origin and evolution of the immune cells. With rapid progress in the study of cell typing in mollusks, research should be expanded to explore the variations of neurotransmitter production and the subsequent autocrine/ paracrine immunomodulation among different types of oyster hemocytes.

\section{ETHICS STATEMENT}

All animal-involving experiments of this study were approved by the Ethics Committee of the Institute of Oceanology, Chinese Academy of Sciences.

\section{REFERENCES}

1. Qiu Y, Peng Y, Wang J. Immunoregulatory role of neurotransmitters. $A d v$ Neuroimmunol (1996) 6:223-31. doi:10.1016/S0960-5428(96)00018-6

2. Franco R, Pacheco R, Lluis C, Ahern GP, O'Connell PJ. The emergence of neurotransmitters as immune modulators. Trends Immunol (2007) 28:400-7. doi:10.1016/j.it.2007.07.005

3. Bafico A, Liu G, Goldin L, Harris V, Aaronson SA. An autocrine mechanism for constitutive Wnt pathway activation in human cancer cells. Cancer Cell (2004) 6:497-506. doi:10.1016/j.ccr.2004.09.032

4. Rinner I, Kawashima K, Schauenstein K. Rat lymphocytes produce and secrete acetylcholine in dependence of differentiation and activation. J Neuroimmunol (1998) 81:31-7. doi:10.1016/S0165-5728(97)00155-0

5. Kawashima K, Fujii T. The lymphocytic cholinergic system and its biological function. Life Sci (2003) 72:2101-9. doi:10.1016/S0024-3205(03)00068-7

6. Flierl MA, Rittirsch D, Nadeau BA, Chen AJ, Sarma JV, Zetoune FS, et al. Phagocyte-derived catecholamines enhance acute inflammatory injury. Nature (2007) 449:721-5. doi:10.1038/nature06185

7. Pacheco R, Gallart T, Lluis C, Franco R. Role of glutamate on T-cell mediated immunity. J Neuroimmunol (2007) 185:9-19. doi:10.1016/j.jneuroim. 2007.01.003

8. Levite M. Nerve-driven immunity. The direct effects of neurotransmitters on T-cell function. Ann N Y Acad Sci (2000) 917:307-21. doi:10.1111/j.17496632.2000.tb05397.x

9. Besser MJ, Ganor Y, Levite M. Dopamine by itself activates either D2, D3 or D1/D5 dopaminergic receptors in normal human T-cells and triggers the selective secretion of either IL-10, TNFalpha or both. J Neuroimmunol (2005) 169:161-71. doi:10.1016/j.jneuroim.2005.07.013

10. Takahashi H, Kobayashi M, Tsuda Y, Herndon DN, Suzuki F. Contribution of the sympathetic nervous system on the burn-associated impairment of CCL3 production. Cytokine (2005) 29:208-14. doi:10.1016/j.cyto.2004.10.014

11. Torres KC, Antonelli LR, Souza AL, Teixeira MM, Dutra WO, Gollob KJ. Norepinephrine, dopamine and dexamethasone modulate discrete leukocyte subpopulations and cytokine profiles from human PBMC. J Neuroimmunol (2005) 166:144-57. doi:10.1016/j.jneuroim.2005.06.006

12. Watanabe Y, Nakayama T, Nagakubo D, Hieshima K, Jin Z, Katou F, et al. Dopamine selectively induces migration and homing of naive CD8+ T cells via dopamine receptor D3. JImmunol (2006) 176:848-56. doi:10.4049/ jimmunol.176.2.848

\section{AUTHOR CONTRIBUTIONS}

ZLi, LS, LW, ML, and ZZ conceived and designed the experiments. ZLi performed the experiments. ZLi, ZZ, and QY analyzed the data. LQ contributed reagents/materials/analysis tools. WW and $\mathrm{ZLv}$ contributed to the discussion. ZLi, LW, and LS wrote the manuscript. All the authors read and approved the final manuscript.

\section{ACKNOWLEDGMENTS}

We are grateful to all the laboratory members for their technical advice and helpful discussions.

\section{FUNDING}

This research was supported by grants (no. U1706204) from National Science Foundation of China, AoShan Talents Cultivation Program Supported by Qingdao National Laboratory for Marine Science and Technology (no. 2017ASTCP-OS13), the Fund for Outstanding Talents and Innovative Team of Agricultural Scientific Research, Dalian High Level Talent Innovation Support Program (2015R020), the Research Foundation for Talented Scholars in Dalian Ocean University (to LW), and the Distinguished Professor of Liaoning (to LS).

13. Hartenstein V. The neuroendocrine system of invertebrates: a developmental and evolutionary perspective. J Endocrinol (2006) 190:555-70. doi:10.1677/ joe.1.06964

14. Song L, Wang L, Zhang H, Wang M. The immune system and its modulation mechanism in scallop. Fish Shellfish Immunol (2015) 46:65-78. doi:10.1016/j. fsi.2015.03.013

15. Liu Z, Zhou Z, Jiang Q, Wang L, Yi Q, Qiu L, et al. The neuroendocrine immunomodulatory axis-like pathway mediated by circulating haemocytes in Pacific oyster Crassostrea gigas. Open Biol (2017) 7. doi:10.1098/rsob.160289

16. Zhou Z, Wang L, Gao Y, Wang M, Zhang H, Wang L, et al. A monoamine oxidase from scallop Chlamys farreri serving as an immunomodulator in response against bacterial challenge. Dev Comp Immunol (2011) 35:799-807. doi:10.1016/j.dci.2011.03.014

17. Shi X, Zhou Z, Wang L, Yue F, Wang M, Yang C, et al. The immunomodulation of acetylcholinesterase in Zhikong scallop Chlamys farreri. PLoS One (2012) 7:e30828. doi:10.1371/journal.pone.0030828

18. Zhou Z, Wang L, Shi X, Yue F, Wang M, Zhang H, et al. The expression of dopa decarboxylase and dopamine beta hydroxylase and their responding to bacterial challenge during the ontogenesis of scallop Chlamys farreri. Fish Shellfish Immunol (2012) 33:67-74. doi:10.1016/j.fsi.2012.04.002

19. Zhou Z, Wang L, Shi X, Zhang H, Gao Y, Wang M, et al. The modulation of catecholamines to the immune response against bacteria Vibrio anguillarum challenge in scallop Chlamys farreri. Fish Shellfish Immunol (2011) 31:1065-71. doi:10.1016/j.fsi.2011.09.009

20. Shi X, Wang L, Zhou Z, Yang C, Gao Y, Wang L, et al. The arginine kinase in Zhikong scallop Chlamys farreri is involved in immunomodulation. Dev Comp Immunol (2012) 37:270-8. doi:10.1016/j.dci.2012.03.008

21. Sternberg EM. Neural regulation of innate immunity: a coordinated nonspecific host response to pathogens. Nat Rev Immunol (2006) 6:318-28. doi:10.1038/nri1810

22. Malagoli D, Mandrioli M, Tascedda F, Ottaviani E. Circulating phagocytes: the ancient and conserved interface between immune and neuroendocrine function. Biol Rev Camb Philos Soc (2017) 92:369-77. doi:10.1111/brv.12234

23. Ottaviani E, Malagoli D, Franceschi C. Common evolutionary origin of the immune and neuroendocrine systems: from morphological and functional evidence to in silico approaches. Trends Immunol (2007) 28:497-502. doi:10.1016/j.it.2007.08.007

24. Ottaviani E. The mollusc as a suitable model for mammalian immuneneuroendocrine investigations. Invertebrate Surviv J (2004) 1:2-4. 
25. Ottaviani E, Caselgrandi E, Franchini A, Franceschi C. CRF provokes the release of norepinephrine by hemocytes of Viviparus ater (Gastropoda, Prosobranchia): further evidence in favour of the evolutionary hypothesis of the mobile immune-brain. Biochem Biophys Res Commun (1993) 193:446-52. doi:10.1006/bbrc.1993.1644

26. Jiang Q, Zhou Z, Wang L, Yang C, Wang J, Wu T, et al. Mutual modulation between norepinephrine and nitric oxide in haemocytes during the mollusc immune response. Sci Rep (2014) 4:6963. doi:10.1038/srep06963

27. Zhou Z, Jiang Q, Wang M, Yue F, Wang L, Wang L, et al. Modulation of haemocyte phagocytic and antibacterial activity by alpha-adrenergic receptor in scallop Chlamys farreri. Fish Shellfish Immunol (2013) 35:825-32. doi:10.1016/j.fsi.2013.06.020

28. Shi X, Zhou Z, Wang L, Wang M, Shi S, Wang Z, et al. The immunomodulation of nicotinic acetylcholine receptor subunits in Zhikong scallop Chlamys farreri. Fish Shellfish Immunol (2015) 47:611-22. doi:10.1016/j.fsi.2015.10.001

29. Liu Z, Zhou Z, Wang L, Dong W, Qiu L, Song L. The cholinergic immune regulation mediated by a novel muscarinic acetylcholine receptor through TNF pathway in oyster Crassostrea gigas. Dev Comp Immunol (2016) 65:139-48. doi:10.1016/j.dci.2016.07.003

30. Caulfield MP, Birdsall NJ. International Union of Pharmacology. XVII. Classification of muscarinic acetylcholine receptors. Pharmacol Rev (1998) 50:279-90.

31. Regan JW, Kobilka TS, Yangfeng TL, Caron MG, Lefkowitz RJ, Kobilka BK. Cloning and expression of a human-kidney CDNA for an alpha-2-adrenergic receptor subtype. Proc Natl Acad Sci U S A (1988) 85:6301-5. doi:10.1073/ pnas.85.17.6301

32. Rathz DA, Brown KM, Kramer LA, Liggett SB. Amino acid 49 polymorphisms of the human beta(1)-adrenergic receptor affect agonist-promoted trafficking. J Cardiovasc Pharmacol (2002) 39:155-60. doi:10.1097/00005344200202000-00001

33. Ma SP, Ren LM, Zhao D, Zhu ZN, Wang M, Liu HG, et al. Chiral selective effects of doxazosin enantiomers on blood pressure and urinary bladder pressure in anesthetized rats. Acta Pharmacol Sin (2006) 27:1423-30. doi:10.1111/j.1745-7254.2006.00443.x

34. Liu Z, Wang L, Zhou Z, Sun Y, Wang M, Wang H, et al. The simple neuroendocrine-immune regulatory network in oyster Crassostrea gigas mediates complex functions. Sci Rep (2016) 6:26396. doi:10.1038/srep26396

35. Schmittgen TD, Livak KJ. Analyzing real-time PCR data by the comparative C(T) method. Nat Protoc (2008) 3:1101-8. doi:10.1038/nprot.2008.73

36. Livak KJ, Schmittgen TD. Analysis of relative gene expression data using realtime quantitative PCR and the 2(-Delta Delta C(T)) method. Methods (2001) 25:402-8. doi:10.1006/meth.2001.1262

37. Shi X, Wang L, Zhou Z, Liu R, Li Y, Song L. Acetylcholine modulates the immune response in Zhikong scallop Chlamys farreri. Fish Shellfish Immunol (2014) 38:204-10. doi:10.1016/j.fsi.2014.03.008

38. Goldstein M, Freedman LS, Bonnay M. An assay for dopamine-betahydroxylase activity in tissues and serum. Experientia (1971) 27:632-3. doi:10.1007/BF02136929

39. Xuereb B, Lefevre E, Garric J, Geffard O. Acetylcholinesterase activity in Gammarus fossarum (Crustacea Amphipoda): linking AChE inhibition and behavioural alteration. Aquat Toxicol (2009) 94:114-22. doi:10.1016/j. aquatox.2009.06.010

40. Levite M. Neurotransmitters activate T-cells and elicit crucial functions via neurotransmitter receptors. Curr Opin Pharmacol (2008) 8:460-71. doi:10.1016/ j.coph.2008.05.001

41. Fuji T, Yamada S, Misawa H, Tajima S, Fujimoto K, Suzuki T, et al. Expression of choline acetyltransferase mRNA and protein in T-lymphocytes. Proc Japan Acad (1995) 71B:231-5. doi:10.2183/pjab.71.231

42. Amenta F, Tayebati SK. Pathways of acetylcholine synthesis, transport and release as targets for treatment of adult-onset cognitive dysfunction. Curr Med Chem (2008) 15:488-98. doi:10.2174/092986708783503203

43. Robertson D, Haile V, Perry SE, Robertson RM, Phillips JA III, Biaggioni I. Dopamine beta-hydroxylase deficiency. A genetic disorder of cardiovascular regulation. Hypertension (1991) 18:1-8. doi:10.1161/01.HYP.18.1.1

44. Wu D, Hersh LB. Choline acetyltransferase: celebrating its fiftieth year. J Neurochem (1994) 62:1653-63. doi:10.1046/j.1471-4159.1994.62051653.x

45. Kaufman S, Friedman S. Dopamine-beta-hydroxylase. Pharmacol Rev (1965) 17:71-100.
46. Junger WG. Immune cell regulation by autocrine purinergic signalling. Nat Rev Immunol (2011) 11:201-12. doi:10.1038/nri2938

47. Kondo Y, Tachikawa E, Ohtake S, Kudo K, Mizuma K, Kashimoto T, et al. Inflammatory cytokines decrease the expression of nicotinic acetylcholine receptor during the cell maturation. Mol Cell Biochem (2010) 333:57-64. doi:10.1007/s11010-009-0204-4

48. Guo Y, Wang L, Zhou Z, Wang M, Liu R, Wang L, et al. An opioid growth factor receptor (OGFR) for [Met5]-enkephalin in Chlamys farreri. Fish Shellfish Immunol (2013) 34:1228-35. doi:10.1016/j.fsi.2013.02.002

49. Liu Z, Zhou Z, Wang L, Jiang S, Wang W, Zhang R, et al. The immunomodulation mediated by a delta-opioid receptor for [Met(5)]-enkephalin in oyster Crassostrea gigas. Dev Comp Immunol (2015) 49:217-24. doi:10.1016/j. dci.2014.11.017

50. Li M, Qiu L, Wang L, Wang W, Xin L, Li Y, et al. The inhibitory role of gamma-aminobutyric acid (GABA) on immunomodulation of Pacific oyster Crassostrea gigas. Fish Shellfish Immunol (2016) 52:16-22. doi:10.1016/j. fsi.2016.03.015

51. Dani JA, Bertrand D. Nicotinic acetylcholine receptors and nicotinic cholinergic mechanisms of the central nervous system. Annu Rev Pharmacol Toxicol (2007) 47:699-729. doi:10.1146/annurev.pharmtox.47.120505.105214

52. Kawashima K, Fujii T, Moriwaki Y, Misawa H. Critical roles of acetylcholine and the muscarinic and nicotinic acetylcholine receptors in the regulation of immune function. Life Sci (2012) 91:1027-32. doi:10.1016/j.lfs.2012. 05.006

53. Yoshikawa H, Kurokawa M, Ozaki N, Nara K, Atou K, Takada E, et al. Nicotine inhibits the production of proinflammatory mediators in human monocytes by suppression of I-kappaB phosphorylation and nuclear factor-kappaB transcriptional activity through nicotinic acetylcholine receptor alpha7. Clin Exp Immunol (2006) 146:116-23. doi:10.1111/j.1365-2249.2006.03169.x

54. Fujii T, Watanabe Y, Inoue T, Kawashima K. Upregulation of mRNA encoding the M5 muscarinic acetylcholine receptor in human T- and B-lymphocytes during immunological responses. Neurochem Res (2003) 28:423-9. doi:10.1 023/A:1022840416292

55. Qin K, Sethi PR, Lambert NA. Abundance and stability of complexes containing inactive $\mathrm{G}$ protein-coupled receptors and $\mathrm{G}$ proteins. FASEB J (2008) 22:2920-7. doi:10.1096/fj.08-105775

56. Chen-Izu Y, Xiao RP, Izu LT, Cheng H, Kuschel M, Spurgeon H, et al. $\mathrm{G}(\mathrm{i})$-dependent localization of beta(2)-adrenergic receptor signaling to L-type $\mathrm{Ca}(2+)$ channels. Biophys $J$ (2000) 79:2547-56. doi:10.1016/ S0006-3495(00)76495-2

57. Grisanti LA, Perez DM, Porter JE. Modulation of immune cell function by alpha(1)-adrenergic receptor activation. Curr Top Membr (2011) 67:113-38. doi:10.1016/B978-0-12-384921-2.00006-9

58. Hasko G, Szabo C. Regulation of cytokine and chemokine production by transmitters and co-transmitters of the autonomic nervous system. Biochem Pharmacol (1998) 56:1079-87. doi:10.1016/S0006-2952(98)00153-1

59. Sajjadi FG, Takabayashi K, Foster AC, Domingo RC, Firestein GS. Inhibition of TNF-alpha expression by adenosine: role of A3 adenosine receptors. J Immunol (1996) 156:3435-42.

60. Wang H, Yu M, Ochani M, Amella CA, Tanovic M, Susarla S, et al. Nicotinic acetylcholine receptor alpha7 subunit is an essential regulator of inflammation. Nature (2003) 421:384-8. doi:10.1038/nature01339

61. Spengler RN, Allen RM, Remick DG, Strieter RM, Kunkel SL. Stimulation of alpha-adrenergic receptor augments the production of macrophage-derived tumor necrosis factor. J Immunol (1990) 145:1430-4.

62. Wang L, Qiu L, Zhou Z, Song L. Research progress on the mollusc immunity in China. Dev Comp Immunol (2013) 39:2-10. doi:10.1016/j.dci.2012.06.014

Conflict of Interest Statement: The authors declare no competing interests which may be perceived to influence the conduct or analysis of the data.

Copyright (c) $2018 \mathrm{Liu}$, Wang, Lv, Zhou, Wang, Li, Yi, Qiu and Song. This is an open-access article distributed under the terms of the Creative Commons Attribution License (CC BY). The use, distribution or reproduction in other forums is permitted, provided the original author(s) and the copyright owner are credited and that the original publication in this journal is cited, in accordance with accepted academic practice. No use, distribution or reproduction is permitted which does not comply with these terms. 